\title{
Beyond Sound in Sound Art: Society and Politics in the Art of Yasunao Tone and Akio Suzuki
}

\author{
Joseph Tham Chin Pang \\ Crescent Girls' School, Ministry Of Education, Singapore \\ tham_chin_pang@crescent.edu.sg
}

\begin{abstract}
The history of sound art has been a case of displacement and misplacement. It has been displaced due to the nature of the medium - sound, a phenomenon that is heard and felt but not seen. In a visually dominated world like ours, this spells the relegation of the importance of sound and audio sensitivity in a human's perception, cognition and consciousness. It is misplaced as it is more often categorically subsumed under the other art form, music. Sound art is in fact one of the most ancient of art forms when the name of Greek god of wind, Aeolus, was used to name the Aeolian harp. Sound art has often been defined, in the late 2oth century and early 21st century and by academics and critics, as a novel form of art. Once again it is another case of displacement and misplacement. The two case studies which will be discussed in this paper will foreground the social and political contexts of the artists as well as their responses to these socio-political conditions to demonstrate that sound art, just like any other art forms like paintings, music and theatre, is reflexive of the times of the creators, and more.
\end{abstract}

Keywords: sound art, Japan, politics

\section{Sound Art}

"Machines are designed not to make mistakes, in our behaviour we often make mistakes, so why not machines also. I add that reality to it. So it's not destruction but an addition."

The history of sound art has been a case of displacement and misplacement. It has been displaced due to the nature of the medium sound, a phenomenon that is heard and felt but not seen. In a visually dominated world like ours, this spelt the relegation of the importance of sound and audio sensitivity in a human's perception, cognition and consciousness. Sound art is misplaced as it is more often categorically subsumed under the other art form, music: it is either considered as modern composition, noise, free improvisation or electronica. Sound art is in fact one of the most ancient of art forms: the name of the Greek

\footnotetext{
${ }^{1}$ Yasunao Tone: sound artist, Fluxus artist, composer, and all-round provocateur.
}

god of wind, Aeolus, was used to name the Aeolian harp. It is a wooden instrument well known in the ancient world in the West that is played not by a human agent but instead, via the force of nature, wind. The first instance of sound art is thus both a tribute to the powers of the supernatural as well as the revelling of nature.

Sound art has often been defined, in the late 20 th century and early 21st century and by academics and critics, as a novel form of art ${ }^{2}$. Once again it is another case of displacement

\footnotetext{
2 For more please see: Caleb Kelly (ed.) (2011), Sound, London/Cambridge, MA: Whitechapel Gallery/The MIT Press; Brandon LaBelle (2010), Background Noise Perspectives on Sound Art, London: Continuum Books; and Seth Kin-Cohen (2009), In the Blink of an Ear - Toward a Noncochlear Sonic Art, London: Continuum Books.
} 
and misplacement in the histories of sound art. For the former, sound art is posited as the use of sound to continue the pathway opened up by conceptual artists since the 1960s, albeit focusing on the sonic canvas, the unseen vibrations in the $\mathrm{air}^{3}$, and basically its physical properties $^{4}$. For the latter, it is usually described as apolitical or asocial as the emphasis is always on the sonic properties and its aesthetics and only that ${ }^{5}$. Traditional art criticism and art historical writing of the symbiotic relationships between artwork and the social and political milieu that germinate them are almost always left out. If any of its social and political landscape is mentioned, it is usually tacked conveniently under the general biographies of the artists without further studies of the artists' work with that of their socio-economic context.

The two case studies which will be discussed in this paper will foreground the social

\footnotetext{
${ }^{3}$ In the 1960s and 1970s, sound art did not exist as a form as least in name; many examples cited by anthologies and history texts reveal most as sideway explorations from the then mainstream context of modern composition, so composers/artists like La Monte Young, Tony Conrad, Alvin Lucier, Robert Ashley, Charlotte Moorman/Nam June Paik and many other who worked with them or within their milieu are perceived as early exemplars of proto or pre-sound art practitioners. At the end, the notion of music or intermedia or Fluxus became the convenient categories which many sound art works of the artists were positioned then and retrospectively. See Alan Licht (2007), Sound Art: Beyond Music, Between Categories. New York: Rizzoli.
}

4 Alvin Lucier's "I Am Sitting In A Room" (1969) and Robert Ashley's "Wolfman" (1964) are two classical pieces which are often cited in accounts and books.

${ }^{5}$ Please refer to: Brandon LaBelle \& Steve Roden (eds.) (1999), Site of Sound: Of Architecture \& the Ear, Los Angeles/Santa Monica: Errant Bodies Press/Smart Art Press; Christof Migone (2012), Sonic Somatic, Los Angeles: Errant Bodies Press and footnote 1 . The relative avalanche of literature on sound art and its history since the late 1990s gave the false impression that sound art was an outgrowth of conceptual art or a new form of art to be documented and curated in art spaces. and political contexts of the Akio Suzuki and Yasunao Tone, as well as their responses to these socio-political conditions to demonstrate that sound art, just like any other art forms like paintings, music and theatre, is reflexive of the times of their creators. The two sound artists are from Japan, a country which due to its unique post-World War II history as well as its past before the Pacific War, but they exemplify two different takes on their socioeconomic and political settings since the 1960s. Both artists were born and brought up during the most tumultuous period of time in 2oth century Japan. Both grew up in the strangely schizophrenic era of initial post-War humiliation and extreme poverty and then, taking an abrupt about-turn swiftly to become one of the most powerful nations, economically, within a short span of ten years (late 1940s to late 1950s). The military antagonisms against the USA during the War from 1941 to the devastation of two Japanese cities from the deadliest man-made weapons ever, the atomic bombs in 1945 , left a permanent mark in the national psyche of the Japanese people. The Americans then, due to Cold War politics, decided to reinstall Japan as quickly as possible as it was viewed strategically as a viable ally in the containment of the Communist states in Asia. This led to the subsequent sponsoring of the defeated nation economy to boost its drained capacity to that of global status by the $1960 s^{6}$. The tension produced by such rapid and fortuitous turn-of-events for Japan was viewed apprehensively by many Japanese who experienced these rapidly changing developments.

On one hand the influx of Euro-American ideas and products fed the hunger of the Japanese to seek actively for something else to replace the failed militaristic nationalism of the previous decades, derived culturally and historically. Many saw the opportunities opened up in the post-war years as a great avenue to change Japan fundamentally from its conservative and conformist traditions ${ }^{7}$. On the

6 Julian Cope (2007), Japrocksampler, London: Bloomsbury, pp.23-40.

${ }^{7}$ Ibid., pp.41-72. 
other hand, many also questioned the rampant consumerist-driven materialism brought in by the Americans as threatening the values and morals of the people. Their criticism also extended to the rampant consumerism in Japan. This dichotomy thus presented to artists, writers, and the two artists with the necessary fuel to channel their critique on the politics and society of Japan.

One interesting practice which is discernible in many of the Japanese art collectives and artists emerging in the $1950 \mathrm{~s}$ and $1960 \mathrm{~s}$ demonstrated clear debt to their Japanese culture - the emphasis on simplicity, interconnectedness of things and non-permanence which one can attribute to certain sensibilities of Japanese aesthetics but to Zen Buddhism and Shintoism as well. Key groups like Gutai, Fluxus in Japan and Mono-ha are just some of the more historically well-known examples ${ }^{8}$.

The two following case studies will highlight the significance of such influences and traits commonly found in Japanese works and practices as well as pointing out how these artists channel some of these sensibilities through their choice of art medium - sound.

\section{Back to Nature: A case study of Akio Suzuki}

Born in 1941 in the then Japanese colony of Korea, Akio Suzuki, was repatriated back to Japan with his parents after the War in 1945. Due to the cultural import of Euro-American influences, Suzuki was exposed to the ideas of iconoclasts like John Cage and David Tudor and their then-revolutionary introduction of chance and conceptual bent to the arts ${ }^{9}$. In 1963, Suzuki was working in an architect's office and he became fascinated by an idea. He was examining the possibility of making a staircase that would not tire out the users but in fact would become a pleasure to them. Then it occurred to him that he could conceive of a staircase that would look like a musical stave

\footnotetext{
${ }^{8}$ For more details see Alexandra Munroe (1994), Japanese Art After 1945 - Scream Against The Sky, New York: Harry N. Abrams.

9 David Toop, "Akio Suzuki - Acoustic Trickster" in The Wire issue 231 May 2003, p.12.
}

and if he would to drop a ping pong ball down it, the sounds created should correspondingly be beautiful. This spurred him on to start on his first actions, which Suzuki coined Self Study Events ${ }^{10}$. He went to a train station in Nagoya and he tipped a dustbin down a staircase. The sounds created was horrible and he was in fact, looked at with disdain by the public as many of them picked up the rubbish which was scattered all over the base of the staircase.

It was perceived by other Japanese as an act of public nuisance and was considered inappropriate social behaviour. Undeterred, he threw down another bin, and was arrested by the police $^{11}$. Suzuki's first work challenged norms and provoked thought in the parts of Japanese society that are particular with etiquette.

Similar to many Happenings which were taking place in the major cities of Japan due to the absorption of such creative but provocative acts critiquing the societies in the West, the authority and the crass consumerism many of these artists witnessed around them, Suzuki found the experiments (like the one described above) to be unsatisfactory, and he decided to conduct his own research to help boost himself intellectually and to help him understand the world around him better. This was, he hoped, to provide ideas for him to come up with more meaningful and more impactful artistic endeavours in the post-War years. He subsequently developed Throwing and Following. He would project sound into a space and he would follow the consequential resonance of it in the time and space. This opened him up to a better understanding of the objects around him and in turn he could use them more effectively to generate sounds in spaces ${ }^{12}$. He thus gradually grasped the interactivity between material, sonic properties of objects, and the resonances and echoes produced. This laid the foundation for his mature works in the 1970s.

In the 1970s Suzuki hand crafted one of his most signature sound art tools, the Analapos. It is built from two cylindrical resonators connected by long springs. The instrument ex-

\footnotetext{
10 Ibid.

11 Ibid.

12 Ibid.
} 
plores the reverberation of springs, the resonance of vessels and the transmission of signals between two physically linked terminals. The tool also reacts differently from space to space as the reverberation and resonances generated vary from one venue to another. The simplicity of the tools belies a few principal ideals of Suzuki: his subtle commentary on the hyper-modernisation of the Japanese society and the growing estrangement between individuals in such a materialist-driven, dogeat-dog environment with the overemphasis on science, technology and human agency. Just like most of his sound art pieces/performance works, Suzuki wants to reclaim the human-ness of art by consciously interweaving human agency with the implements/instruments. He also wants to alert his audience/listeners to pay attention to their surroundings once again. He has since the 1970 increasingly performed in open or natural settings, inviting the audiences to join him in such back-to-nature creation of his sound art. This can perhaps be linked back to the Japanese religious and aesthetic reverence of nature but can also be interpreted as a veiled rejection of the modernist project of relentless human progression in its scientific and technological drive since the 19th century.

Coming back to the Analapos, its use in the wide-open natural context can reap surprising results as the tool reacts in indeterminate manners with the winds, the humidity, the openness and altitude of the space as well as the resonating human bodies in its vicinity ${ }^{13}$. No single event can be repeated. This reflects prominently the unpredictability of nature and the state of our world.

Suzuki also created site-specific events that required the audience to travel to a space close to his current residence in Tango, Japan, to immerse themselves in the piece with him, his installation space and the elements. Suzuki calls the venue his dream space and he constructed and coined it Space in the Sun (1988). The venue is found on a mountaintop in rural Tango under the direct purview of the sun. The site consists of two crumbling and identical 17 meters by 3.5 meters facing walls. The walls were built from 20,000 handmade sun-baked loam bricks. They are separated by a 7 meters floor space constructed from the same materials as the walls ${ }^{14}$. There are many "imperfections" found at the site such as the almost ubiquitous cowpats left there by the herds that visited the site daily. The howling winds that surge through and around the walls can be deafening. Once in a while, one can hear the odd birdcall, a lowing cow or the distant farm machinery. As one strolls through the site, the sounds come together to suggest a confluence of nature and man-make phenomenon around us even in such rural settings as Tango ${ }^{15}$. Akio Suzuki's intentions are thus not so much of a rejection of human agency and modernisation in a simplistic fashion but instead Suzuki is presenting to us a conundrum of the natureversus-human essentialism of man. With regards to Suzuki's nature-based works, his good friend and writer in Japan, Shin Nakagawa, wrote, "The act of listening to Nature while at the same time destroying Nature forms an interesting contrast ${ }^{16}$." For one to reject human agency, in fact, still involves actively, the agency of man on the chosen site of return.

Akio Suzuki's sound art and works therefore stemmed from his understanding of the dilemma of modern Japan as well as modern society as a whole. This explains why his works are simultaneously parochial and universal in its message and therefore in the 1980s when he participated in Documenta 8 (Kassel, 1987), he received rapturous response from all in attendance. While we go back to nature to embrace it we are still interfering with it. When one critiques the process of modernisation and its supposed ills, one needs to realise the inevitability of human agency on this planet. Suzuki's relatively understated comments on the world via his sound art is thus thoughtprovoking and they force us to delve deeper into the interconnectedness of things and to see beyond the black-and-white of things which most people are so conveniently latch-

\footnotetext{
14 Biba Kopf, "Global Ear: Tango/Sapporo" in The Wire issue 239 January 2004, p.14.

${ }^{15} \mathrm{Ibid}$.

16 Ibid.
} 
ing onto when critiquing the world around them ${ }^{17}$. He is thus not providing a didactic answer but through his works we can perhaps be triggered to contemplate a bit more: humans are maybe too egotistical to lay all blame on human agency as Nature often fights back or react to us in mysterious ways which we can never predict. Suzuki does not romanticise about nature; he is more concerned about the often ignored symbiotic relationship between the natural world and humans and he has been trying to remind us again and again through his works.

\section{Taking Technology by its horns: The many tales of Yasunao Tone}

Yasunao Tone was born in 1935 in Tokyo, Japan. He witnessed the atrocities of the war when the Allied planes carpet-bombed Tokyo on a daily basis towards the end of the war. The surrender of Japan after the dropping of the two horrifying atomic bombs and the subsequent events in Japan and its initial heinous existence in the first post-war years was experienced first-hand by Tone. However like many who grew up and were being exposed to the influx of Western modernist ideas and books in the 1950s, the cultural environment provided creative and cultural fuel for him and many to embrace modernism. Neither a trained musician nor artist, Tone went to Chiba University to study literature ${ }^{18}$. This did not stop him from exploiting the world around him for creative ends. He first dived into "music" making not of a conventional manner but that of a Surrealist and Abstract Expressionist type. According to Tone, "We thought... our improvisational performance could be a form of automatic writing, in a sense that the drip painting of Jackson Pollock was a form of automatic writing."

Tone formed the music group, Group Ongaku in the 1950 s with his fellow enthusi-

\footnotetext{
17 Akio Suzuki, "Akio Suzuki" in Yang, Yeung (ed.) (2010), Pocket: 1 - Around, Hong Kong: Soundpocket, p.82.

${ }^{18}$ Alan Licht, "Yasunao Tone - Random Tone Bursts" in The Wire issue 223 September 2002, p.31.
}

asts and an archival $C D / L P^{19}$ of the group was released in recent years which shocked many as their pieces sounded like the works of equivalent outfits in Euro-America like AMM, MEV and Gruppo Di Improvvisazione Nuova Consonanza $^{20}$ (which featured renown film composer Ennio Morricone), even though Tone and company were earlier than them ${ }^{21}$. Group Ongaku's counterparts in the West were all formed in the mid to late 1960 s and this provides ample evidence challenging the common historical narrative that the West has always been the avant-garde in modern arts and culture. He also linked up with the key artists of the Japanese art and music avant-garde in the late 1950 and 1960s: Takehisa Kosugi (who founded the acclaimed performance group Taj Mahal Travellers in the 1970 s as well as serving his residence as music director of Merce Cunningham Dance Company later that decade), Yoko Ono, infamous Japanese performance art group Hi Red Centre and avantgarde composer Ichiyanagi Toshi (who amongst many, worked with John Cage and polymath poet, director and playwright Shuji Terayama ${ }^{22}$ ). He was involved in the Hi Red Centre anti-Olympic performance piece during the Tokyo Olympics of 1964, Cleaning Piece, which saw him and other participants and posed as street cleaners in the business district of Ginza, stopping traffic for three hours and in fact receiving cooperation from the unknowing police $^{23}$. Tone was working and collaborating

\footnotetext{
${ }^{19}$ The recordings were edited from two sessions of music-making: the first took place on May 81960 and the second session happened on September 16 1961.

${ }^{20}$ AMM, a British group, and MEV, a largely expat American collective in Rome, were formed in the mid-1960s in Britain and Italy respectively while Gruppo started in 1964 in Italy.

${ }^{21}$ Licht, The Wire issue 223, p.31.

${ }^{22}$ William A. Marotti, "Sounding the Everyday: the Music group and Yasunao Tone's early work" in Various (2007), Yasunao Tone: Noise Media Language, Los Angeles: Errant Bodies Press, pp. 1333.

${ }^{23}$ Cope, pp.54-57.
} 
actively in a milieu that demonstrated rabid interdisciplinary intent and even bordererasing outcomes that had clear resonance with the utopian and counter-cultural fervour felt by so many artists in both Japan and the West during the 1960s.

Similarly, Suzuki was also a key member of the Fluxus movement in Japan and he contributed tapes and scores to Fluxus founder George Maciunas and he was involved in the performances of Fluxus pieces in Japan in the $1960 s$ and in New York later. His penchant for irreverence prompted him to comment in recent years that Fluxus was only properly historically meaningful from 1962-66, and that while the works are being exhibited in the museums today, to him it meant that these works are being stripped of their original intentions and functions of being handled and played by both the artists and the audiences ${ }^{24}$. The same spirit gleaned here is similar to Tone's artistic purpose and the conceptualisation of his sound art that he started creating in the 1960s. His disdain and questioning of modern technology in the post-World-War-II world and the associated techno-fetish of modern society to any new fanged media/technology basically served as fodder for his deconstruction and reconceptualisation of some of these technological products in his sound art.

Despite Tone's key role in the various contemporary art fields since the 1950s, he was a relative unknown figure until recently. This was due to the fact that his works from the 1950 s to the 1970 s were largely real-time happenings and performance pieces with little documentation. It was also due to the fact that Tone was residing far away from the world cultural capitals (i.e. the West) that he suffered from the more European-American biased focus on Fluxus, the Happenings and related art movements in Euro-America by critics and historians in those years. Only when he went to New York in 1972 he became more open to the idea of documenting his works, particularly with the advent of improved recording technologies in sound and video at that time.

${ }^{24}$ Licht, p.31.
Tone's most famous work is his mid-1980s "wounded CDs". The direct inspiration of this phase of his works was a book entitled Science Seminar For The Familiar ${ }^{25}$. The part which captured Tone's imagination was a chapter on digital recording, which highlighted to him the error correction programme in $C D$ players which kicks in if a one is misread as zero in the machine's binary codes. Since the error creates a totally different sound, unknown of, he then embarked on a path to override the error correcting system. Eventually, a friend suggested putting adhesive tape with many pinholes in it on the $C D$ itself ${ }^{26}$. The initial impressions one gets upon hearing the outcomes when these "wounded" CDs are played in the machines are that of typical CD skipping/malfunctioning due to surface blemishes. The actual mechanism behind, however, is more than that. As Tone shared, "... numbers are altered so it becomes totally different information. The Scotch tape enables me to make burst errors without significantly affecting the system and stopping the machine ${ }^{27}$." Tone's interventions in the process of the readings of CDs are actually acts of creative noise. By disrupting the machines that are supposed to be the state of the art technology back in the 1980s when the world was moving from the analogue to the digital in many fields of everyday science, Tone successfully questioned and re-inscribed the supposed prescribed workings of an increasingly ordered contemporaneity of the triumphant neo-liberal capitalist paradigm.

Tone wants to interrogate the triumphalism of new scientific and technological "breakthroughs" in the post-War years. With every new product such as this, the media and the corporations together will seemingly snap into a frenzy to valorise the "invincibility" of the product. The fascination with the new and technologically clued-in perpetuates wave after wave of consumer craze to replace existing goods to embrace the new blindly. For example, when the 12-inch vinyl album appeared in the market in the 1960s, it swiftly overtook the

\footnotetext{
${ }^{25}$ Licht, p.32.

${ }^{26}$ Ibid.

${ }^{27}$ Ibid.
} 
previously dominant 7-inch vinyl single format. And when CDs were introduced into the market in the 1980 s with the promise amongst many, of its longer playtime, the needlessness to flip the disc over after 20 minutes and of course the purportedly indestructible nature of the $C D$ sent the consumer markets all over to discard the vinyl format to the small shiny plastic discs. Tone's experiments question this notion head-on: are new technologies necessary and necessarily better? He seems to be probing a deeper issue of that of an uncritical celebration of contemporary scientism and modernisation around the world.

To bring his irreverence and critical interrogation for technology up-to-date, Tone ventures into interrogating the next big thing in recent years - MP3 files. In 2009, Tone started collaborating with a team of the New Aesthetics in Computer Music (NACM) at Music Research Centre at the University of York in UK in $2009^{28}$. Tone wished to develop new software based on the disruption of the MP3. Originally Tone wanted to explore the intervention of the $\mathrm{MP}_{3}$ as reproducing device by interfering with the interface across its main elements (the ones and zeros), the compression encoder and decoder. However, the initial outcomes were unsatisfactory, as they did not much affect the sonic output of the playback of the CDs. Then Tone and his team discovered that by corrupting the sound file in the $\mathrm{MP}_{3}$ format, it would lead to the generation of error messages which could be utilised to assign various lengths of samples automatically. By combining the different playing speeds of the samples, it could produce unpredictable and unknowable sound. To further enrich the software, Tone's team also incorporated other possible elements into the software like flipping stereo channels and phasing ranges that would produce different pitches and timbres ${ }^{29}$.

Tone used the software as a performance art tool several times at the MRC at the University of York. He has since also performed in public in Kyoto, Japan, in May 2009 as well as

\footnotetext{
${ }^{28}$ Yasunao Tone, in sleevenotes to CD album, MP3 Deviations \#6+7.
}

${ }^{29}$ Ibid.
New York City in 2010 and many more subsequent events lined up. He has also produced a $C D$ documenting his performances of his pieces using the said software (Figure 1).

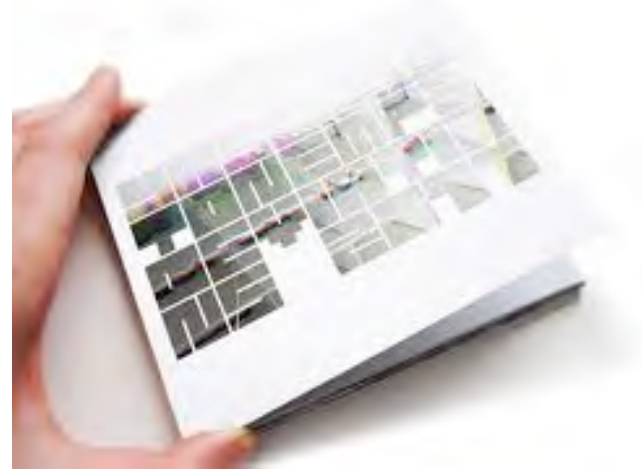

Figure 1. Yasunao Tone's MP Deviations \#6+7 $C D$ Cover. Editions Mego/Peter Rehberg; used with permission.

While the conceptualisation and eventual production/utilisation of the software might be as irreverent as Tone's wounded CDs but it is consistent with Tone's subtle but consistent socio-political critique and his artistic harnessing of the latest consumer-based technology. Even though the first converting, uploading and sharing of $\mathrm{MP}_{3}$ files of existing $\mathrm{CDs}$ into the internet in the mid-1990s began more as an act of wilful rebellion, Tone wanted to examine the by-now ubiquitous format on which contemporary life relies upon - the ones and zeros head on. In fact, the $\mathrm{MP}_{3}$ format not only allows the ease of transfer and sharing of data but it is almost physically empty except for its physical carriers and vehicles like computer hard disks, mobile phones and the Cloud. Like most other consumer technologies, $\mathrm{MP}_{3}$ (or other extant formats such as $\mathrm{MP}_{4}$ ) seems to be used by people merely as a medium of consumption of everyday life for entertainment, work and connecting with others. Most do not see the (often) possible misuse and abuse of technologies to break out of the 'big corporation' push to leverage on such formats and churn out products endlessly.

Tone and his team recognise the potential of the $\mathrm{MP}_{3}$ to be distorted and reconfigured for creative purposes in music and performance art fields. He wants to demonstrate that modern society can and should break out 
of the passive consumption of technological products and question and thus create using the seemingly static functions of modern technology. Tone's art projects belie the belief that reclaiming the role of an individual and conversely the society to not be enslaved by their new gadgets and toys but to interrogate them and abuse them innovatively.

Yasunao Tone is a humanist who is concerned with not only the society and politics of Japan or his immediate surroundings. It is always an on-going search and re-creation for a more considered human perception and rethink of the relevance and role of science and technology today. His message and agenda is about alerting us to be always circumspective about the impact of technology on all human life at the end of the day.

\section{Conclusion}

Both Yasunao Tone and Akio Suzuki are very interested in the tension of humanity, technological advancement and the natural world we all live in today. The recent nuclear and natural disasters in 2011 in Japan were an alarm for all: despite all our advancement in the sciences, we are still at the mercy of nature as well as our own human-driven scientific follies. Suzuki shows us the way back to nature, but he does not romanticise it. In fact, he highlights the irony between humankind embracing and destroying nature concurrently in whatever we do. Tone on the other hand, leads us into the core of new scientific products and deconstructs them to reveal to us the blind spots we have towards technology. Their projects are not about the local society and its parochial views and politics but they are actually about the society and politics of all human kind. In other words, it is about something more universal and all-encompassing.

\section{References}

Adlington, Robert (ed.) (2009), Sound Commitments: Avant-garde Music and the Sixties. New York: Oxford University Press.
Cope, Julian (2007). Japrocksampler. London: Bloomsbury Publishing.

Kelly, Caleb (ed.) (2011). Sound. London \& Cambridge, MA: Whitechapel Gallery \& The MIT Press.

Kim-Cohen (2009), Seth. In the Blink of an Ear: Toward a Non-cochlear Sonic Art. London: Continuum Books.

Kopf, Biba. "Global Ear: Tango/Sapporo"The Wire issue 239 January 2004 14. London: The Wire, 2004 .

LaBelle, Brandon (2010). Background Noise Perspectives on Sound Art. London: Continuum Books.

LaBelle, Brandon and Steve Roden (eds.) (1999). Site of Sound: Of Architecture \& the Ear. Los Angeles \& Santa Monica: Errant Bodies Press \& Smart Art Press.

Licht, Alan (2007). Sound Art: Beyond Music, Between Categories. New York: Rizzoli.

Licht, Alan. "Yasunao Tone - Random Tone Burst" in The Wire issue 223 September 2002 30-33. London: The Wire, 2002.

Migone, Christof (2012). Sonic Somatic: Performance of the Unsound Body. Los Angeles: Errant Bodies Press.

Munroe, Alexandra (1994). Japanese Art After 1945: Scream Against the Sky. New York: Harry N. Abrams, Inc.

Suzuki, Akio. K7 Box (CD). ALM Records/Kojima Recordings, Inc. 2007.

Suzuki, Akio. Odds and Ends (2xCD). Hören 2002.

Tone, Yasunao. MP3 Deviations \#6+7 (CD). Editions Mego 2011.

Tone, Yasunao. Yasunao Tone (CD). Asphodel 2003.

Toop, David. "Akio Suzuki - Acoustic Trickster" in The Wire issue 231 May 2003. London: The Wire, 2003.

Toop, David. "On Location - Akio Suzuki: London School of Oriental and African Studies UK" in The Wire issue 218 April 2002. London: The Wire, 2002.

Various (2007). Yasunao Tone: Noise Media Language. Los Angeles: Errant Bodies Press.

Various (2010). Around by Soundpocket 1 Programme Catalogue. Hong Kong: Soundpocket.

Yang, Yeung (ed.) (2010). Pocket: 1 - Around. Hong Kong: Soundpocket. 